\title{
18 Volunteered Geographic Information (VGI) for the Spatial Planning of Flood Evacuation Shelters in Jakarta, Indonesia
}

\author{
Adya Ninggar Laras Kusumo, Diana Reckien, \\ and Jeroen Verplanke
}

\section{CONTENTS}

18.1 Introduction 307

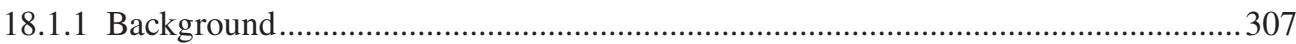

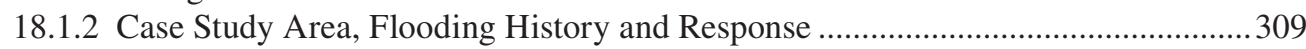

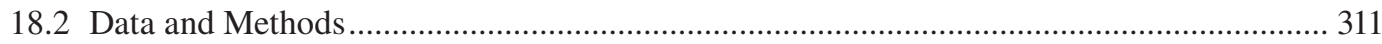

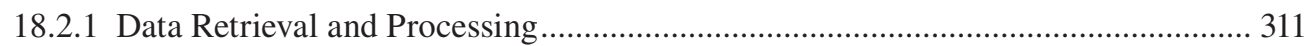

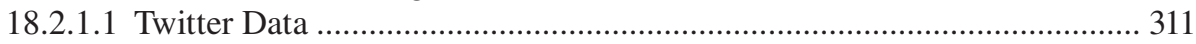

18.2.1.2 Primary Data on Residents' Preferences on Evacuation Shelters.............. 312

18.2.1.3 Secondary Data on Evacuation Shelters .................................................. 312

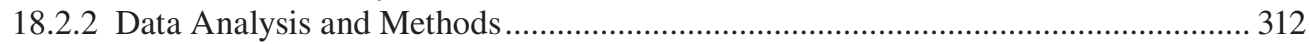

18.2.2.1 Location of Twitter Users in or Near Evacuation Shelters......................... 312

18.2.2.2 Spatial Pattern of Twitter Users in or Near Evacuation Shelters ............... 313

18.2.2.3 Shelter Preferences Among Twitter Users ................................................. 314

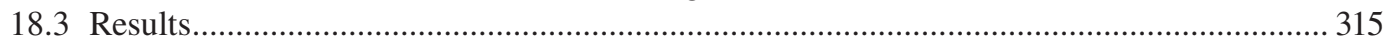

18.3.1 Location of Twitter Users in or Near Evacuation Shelters ..................................... 315

18.3.2 Spatial Pattern of Twitter Users in or Near Evacuation Shelters ............................... 316

18.3.3 Preferences for Evacuation Shelters Among Twitter Users ....................................... 316

18.3.4 Comparison of Sites of Official and Unofficial Evacuation Shelters......................... 318

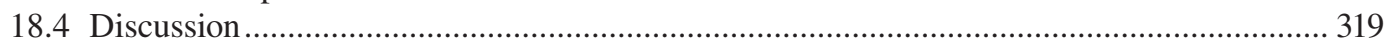

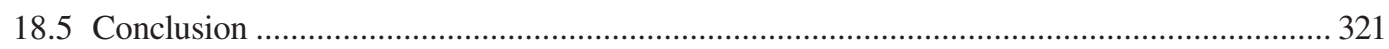

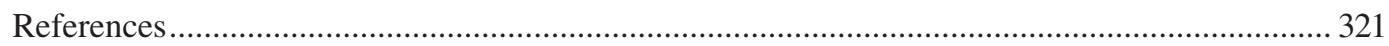

\subsection{INTRODUCTION}

\subsubsection{BACKGROUND}

During disasters and crises, social media have been acknowledged as key communication channels (Wendling et al., 2013). Authorities and emergency response agencies use social media as a valuable source of information, as well as a useful platform for the rapid delivery of it (Kreiner and Neubauer, 2012). Social media assist the response to and management of disasters by, for example, providing a platform for sending alerts, identifying critical needs and focusing responses (Carley et al., 2015). Inhabitants use social media to request help during crises, share views and experiences 
on the events and criticise responses of government agencies and other organizations (Takahashi et al., 2015). Social media thereby allow people to participate in disaster response and management (Goodchild, 2007).

Using social media, people often voluntarily provide data about their own locations - known as volunteered geographic information (VGI). VGI can be made accessible by harnessing tools for assembling and disseminating these geographic data (Goodchild, 2007). In this form, VGI can aid disaster response and management (Takahashi, Tandoc and Carmichael, 2015) by increasing the speed of interaction between victims and relief organizations. Some social media applications, including Twitter ${ }^{\mathrm{TM}}$, Flickr ${ }^{\mathrm{TM}}$ and Open Street Map ${ }^{\mathrm{TM}}$, incorporate VGI by offering a geo-location feature (Schade et al., 2011). All these can be used in situations requiring near real-time disaster response and management (Carley et al., 2015; Kreiner and Neubauer, 2012; Takahashi et al., 2015), both before and during a disaster. VGI is, however, rarely used to address spatial planning problems arising after an extreme weather event or disaster that relate to mitigation of future disasters and/ or climate change adaptation. VGI has considerable potential for such applications and appears to offer advantages over traditional methods. For example, VGI could be used for the planning of sites for evacuation shelters, enabling residents' knowledge and preferences for shelters to be captured in a much faster, more timely and more comprehensive fashion than is possible with, for example, questionnaires and other types of surveys.

The research discussed in this chapter investigates the advantages and disadvantages of using VGI for capturing residents' preferences for (official and unofficial) flood evacuation shelters and explores the usefulness of this information for urban planning. We were motivated to carry out this study by the observation that official evacuation shelters provided by the authorities are frequently not used by residents - a fact known, for example, within Jakarta's city planning department for a long time (one of us works there) and established by research at least 30 years ago (Perry, 1979). A variety of factors determine people's use of official and non-official evacuation shelters (Stein et al., 2010). According to Rahman et al. (2014), these include aspects such as drainage capacity, soils, technical feasibility, shelter capacities, basic facilities present, environmental impact, accessibility, land availability and levels of maintenance. Additional reasons are to be uncovered by our research. We used Twitter data related to flooding in Jakarta, Indonesia to address this objective and the role of VGI.

\section{BOX 18.1 Case Study Area}

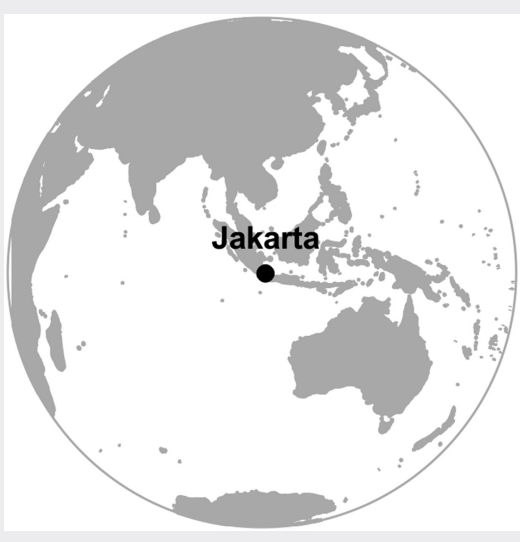

The province of Jakarta or 'Special Capital Region of Jakarta' (DKI Jakarta) is the capital and largest city in Indonesia. Jakarta has an estimated population of over 10 million people in 2016, up from 9,607,787 recorded during the 2010 Census. It is, furthermore, the largest city in Southeast Asia and one of the most populous urban agglomerations on Earth. Jakarta has been selected as case study because of 1) its recurrent problems with flooding and, consequently, its need for a functioning system of flood evacuation shelters; and 2) the popularity of using Twitter among the residents of Jakarta. Flooding affects Jakarta on an almost annual basis and has been an issue since the colonial era. As a response to flood emergencies, the 
Jakarta government's Jakarta Disaster Management Agency (BPBD Jakarta), in collaboration with the SMART Infrastructure Facilities and Twitter, recently provided an online resource known as 'Peta Jakarta'. Peta Jakarta (@petajkt) is a system that utilises social media to gather, sort and display information about flood events in Jakarta in real time (BPBD Jakarta, 2015). In this respect, authorities in Jakarta are among the forerunners in the use of social media for coordinating emergency flooding responses.

\subsubsection{Case Study Area, Flooding History and Response}

The province of Jakarta or 'Special Capital Region of Jakarta' (DKI Jakarta) is the capital of Indonesia (Figure 18.1). Jakarta Province has a total area of $662 \mathrm{~km}^{2}$ and comprises five administrative cities on the mainland and one administrative coastal region that covers the marine area and islands to the north of the mainland. Only the five administrative cities, with their 267 sub-districts, have been considered in our research (see panel on right hand side of Figure 18.1). Jakarta not only is the largest city in Indonesia and the largest city in Southeast Asia but also is one of the most populous urban agglomerations on Earth. Its estimated population was in 2016 greater than 10 million, up from 9,607,787 recorded during the 2010 Census. Jakarta is now considered a global city and home to one of the fastest growing economies in the world (World Population Review, 2018).

Jakarta was selected as a case study because of 1) its recurrent problems with flooding and the need for a functioning system of flood evacuation shelters; and 2) the popularity of using Twitter among Jakarta's residents.

Flooding affects Jakarta almost annually and has been an issue since the colonial era. Historical records show major floods occurred in 1654, 1872, 1909 and 1918 (Team Mirah
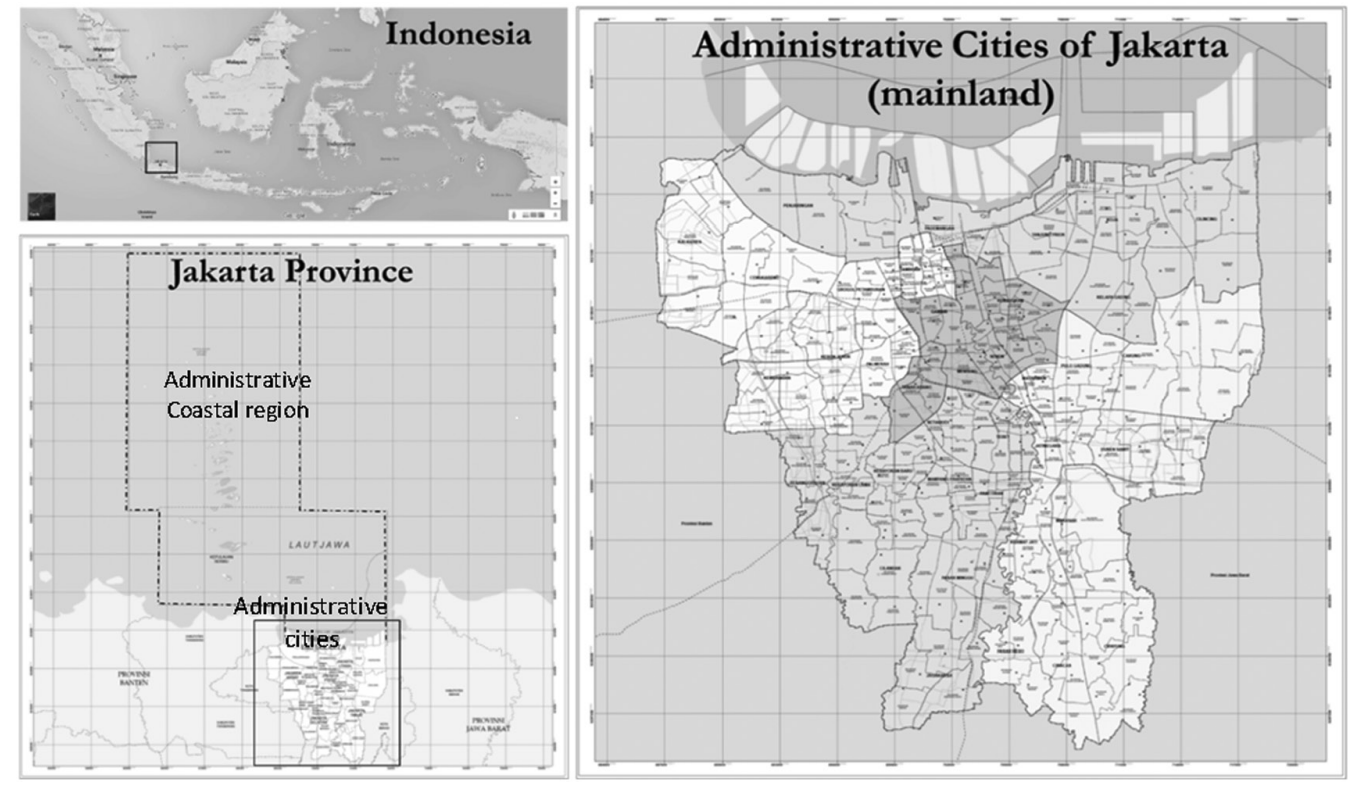

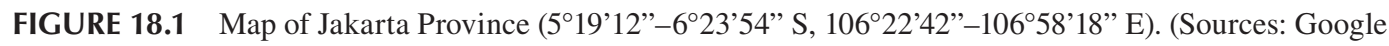
(2015), Jakarta Capital City Government (2014)). 
Sakethi, 2010). Currently, flooding occurs nearly every year. In 2002 and 2007, Jakarta was severely affected by two '50-year' floods' (i.e. floods with a statistical probability of occurring once every 50 years). According to Firman et al. (2011), the 2002 flood covered about one-fifth of Jakarta's total area. Hundreds of thousands of people were made homeless, 68 persons were killed, 190,000 people suffered from flood-related illnesses and about 422,300 had to be evacuated. Flood losses were estimated at 9 trillion Indonesian Rupiahs (USD 998 million) (Akmalah and Grigg, 2011).

As a flood emergency response, the Jakarta Disaster Management Agency (BPBD Jakarta), in collaboration with the SMART Infrastructure Facilities and Twitter, recently launched an online resource known as 'Peta Jakarta'. Peta Jakarta (@petajkt) utilises social media to gather, sort and display information about flood events in Jakarta in real time (BPBD Jakarta, 2015). Jakarta's residents can also use Peta Jakarta to report on situations and conditions in their neighbourhood: information on flooding, evacuation processes, traffic jams and other flood-related problems. One of the reasons behind the development of the Peta Jakarta system was the enormous volume of volunteered geographic information (VGI) being generated by residents of Jakarta through their use of social media, particularly tweets. A tweet is any message posted through Twitter and may contain photos, videos, links and up to 140 characters of text (see http://www.twitter.com). After analysing a sample of 10.6 billion public tweets posted by 517 million Twitter users, Semiocast (2012), social media intelligence consultants, attributed more than $2 \%$ of those tweets to Twitter accounts in Jakarta. This means that Jakarta holds first place as the city most actively using Twitter among all cities worldwide. And, judged by the number of people visiting the Twitter site per month on a country basis (Smart Insights, 2015), Indonesia is recognised as the country with the most Twitter users. In this respect, the authorities in Jakarta are forerunners in the use of social media by using Twitter to coordinate flood emergency response. Given that it can provide a robust sample of Twitter users and its regular exposure to flood emergencies, Jakarta is an appropriate and interesting case for studying the potential of VGI.

\section{BOX 18.2 Methods Applied in the Chapter}

The analysis in this chapter investigates the advantages of using volunteered geographic information (VGI) for capturing residents' preferences for (official and unofficial) flood evacuation shelters and explores the usefulness of VGI for related urban planning tasks. A geographic information system (GIS) was used to buffer the actually recorded location of tweets - to offset inaccuracies during the transmission process and to spatially join the sites of residents' unofficial shelters with the locations of official shelters. These geo-processing tasks were conducted with ESRI ArcGISTM (Version 10.2.2.). Data include secondary data in the form of (1) geo-located Twitter data retrieved from the 'Digital On-line Life and You' (DOLLY) archive using the Twitter Application Program Interface (API); (2) locations of official evacuation shelters and land use categories supplied by the Jakarta City Planning Department (DPK); and (3) the distribution of flood areas supplied by the Jakarta Disaster Management Agency (BPBD Jakarta).

The method could also be applied in cases of other extreme events for which there is a need for an emergency response, for example heat waves and earthquakes. The method has the advantage of relatively easily processing large amounts of VGI and residents' preferences; one disadvantage is the limited insight to be gained from short tweets. It makes sense, therefore, to use VGI in combination with supplementary methods that can provide more insight into residents' location preferences. 


\subsection{DATA AND METHODS}

To establish the usefulness of VGI data for planning the location of evacuation shelters, first we determined the location of Twitter users in or near evacuation shelters. The second step was to determine the spatial pattern of these users in or near specific types of evacuation shelters, followed by the third and last step, which was to determine their preferences regarding the use of these particular types of shelters. Our study employs both secondary and primary data, which was analysed using several methods (Figure 18.2). A description of the retrieval, processing and analysis of the data to carry out the three steps mentioned above follows hereafter.

\subsubsection{Data Retrieval and Processing}

Our study makes use of both primary and secondary data. Primary data was collected to determine the preferences of individuals - Twitter users - regarding shelters. Initially, the preferences were thought to be elicited by way of a questionnaire sent to people that had previously tweeted about their flood experience. However, due to a low response rate for the questionnaire, secondary data had to be used. Secondary data comprised information on Twitter use as well as land-use categories and other spatially explicit GIS data from the statistical offices, i.e. the Jakarta City Planning Department (DPK) and the Jakarta Disaster Management Agency (BPBD Jakarta).

\subsubsection{Twitter Data}

Twitter data was retrieved from the 'Digital On-line Life and You' (DOLLY) archive - the massive database of geo-located Twitter data. Developed by the Floating Sheep collective, the DOLLY Project is a repository of billions of geo-located tweets that allows real-time research and analysis. Building on top of existing open source technology, the Floating Sheep collective has created a back-end that ingests all geo-tagged tweets ( $~ 8$ million a day) and does basic analysis, indexing and geocoding to allow real-time search of the entire database ( 3 billion tweets since December 2011 (Zook et al., 2016)) - using the Twitter Application Program Interface (API). An API is a set of routines, protocols and tools for building software applications. According to Durahim and Coşkun

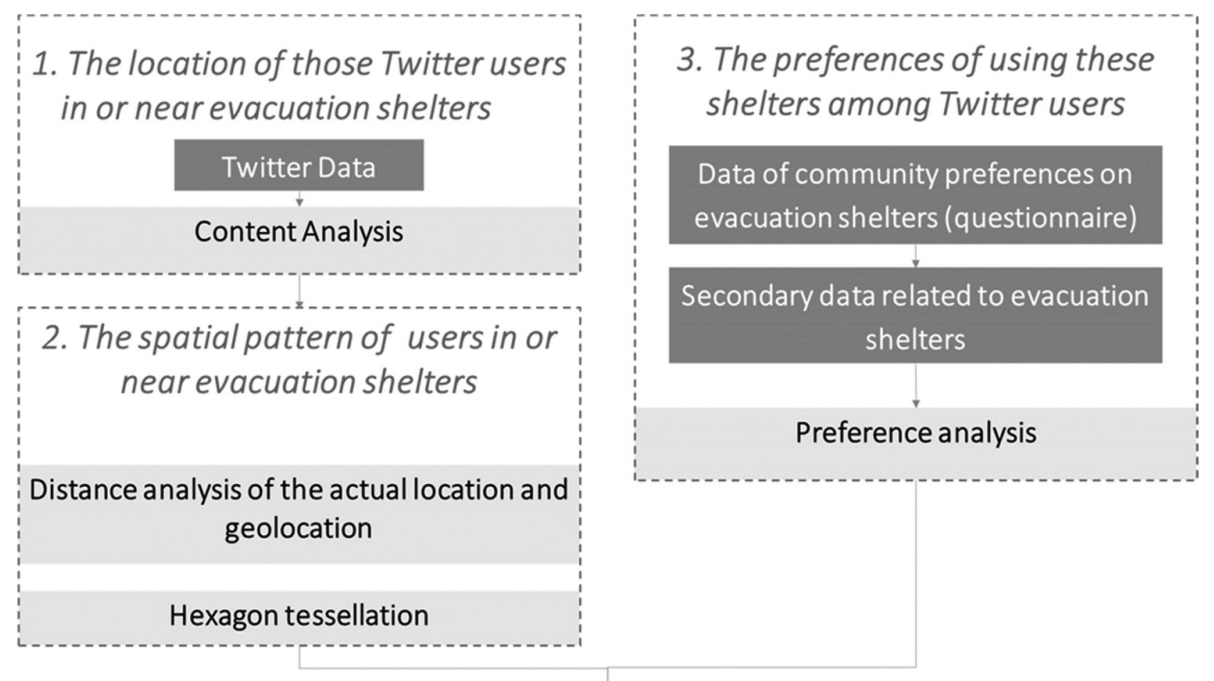

Map of Location Preferences

FIGURE 18.2 Analytical framework. 


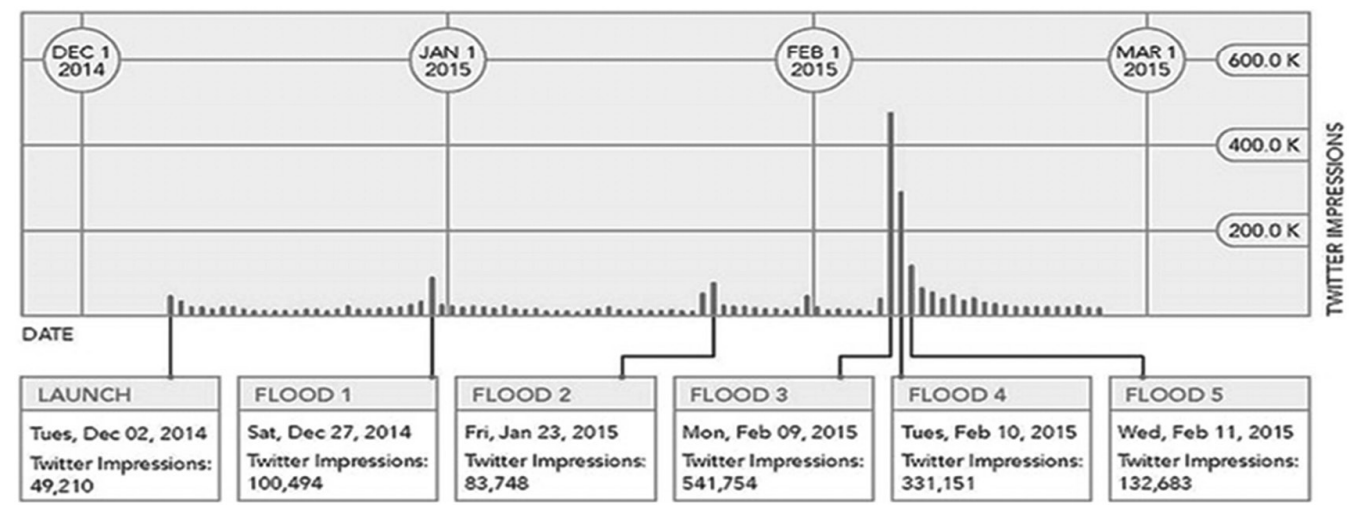

FIGURE 18.3 Twitter impressions during the 2014/15 flooding period (Holderness and Turpin, 2015).

(2015), Twitter API is the means most commonly used to gather data from Twitter. We requested geo-tagged information and received a random sample of $1 \%$ of all geotagged tweets with and without keywords sent in Jakarta. Spatially, the study includes data within the Jakarta bounding box, i.e. between $5.20166^{\circ}$ and $6.37248^{\circ} \mathrm{S}$ and $106.390266^{\circ}$ and $106.974274^{\circ} \mathrm{E}$. As this bounding box does not exactly represent the administrative boundary of Jakarta Province, the data frame was clipped.

Temporally, the study focuses on tweets that were sent during two periods of severe flooding that were categorised by BPBD Jakarta (2015) as events demanding an emergency response. The flood periods analysed were from December 2013 to March 2014 and from December 2014 to March 2015 (Figure 18.3). The retrieved data contain one or more relevant hashtags and keywords, for example \#banjir, \#banjirjkt, \#evakuasi, \#logistik, \#relawan, pengungsi, korban, and @ petajkt. These hashtags and keywords were chosen by the authors (the first author is a native Indonesian living in Jakarta) in cooperation with Mrs Fitria Sudirman from Peta Jakarta (http://www.petajakarta.org). Peta Jakarta was the official operational consultant of DKI Jakarta responsible for managing Twitter reports from residents. The retrieved data therefore represents the locations of Twitter users in Jakarta Province commenting about the floods at the time the flooding was taking place, i.e. during the two periods of major flooding in 2013/14 and 2014/15.

\subsubsection{Primary Data on Residents' Preferences on Evacuation Shelters}

Primary data were initially aimed to capture residents' preferences regarding shelter locations by way of a questionnaire. Residents were selected based on their tweeting behaviour regarding evacuation-shelter locations and their apparent role in the flooding disaster, i.e. residents were identified as evacuees (see Figure 18.4). The questionnaire was designed in Survey Monkey. It contained a mix of open and closed questions about respondents' use of evacuation shelters during previous flood events. The link to the questionnaire was sent to residents through their Twitter accounts.

\subsubsection{Secondary Data on Evacuation Shelters}

Secondary data on the distribution of official evacuation shelters were collected from the Jakarta Disaster Management Agency (BPBD Jakarta) and the Jakarta City Planning Department (DPK). The data were used to compare residents' preferences for shelter locations against the locations of official evacuation shelters. Table 18.1 lists all secondary data types and sources.

\subsubsection{Data Analysis and Methods}

\subsubsection{Location of Twitter Users in or Near Evacuation Shelters}

Content analysis was done in two steps: first, we checked the validity or relevance of the downloaded geo-located Twitter data; second, we performed content classification analysis of relevant tweets (Figure 18.4). 


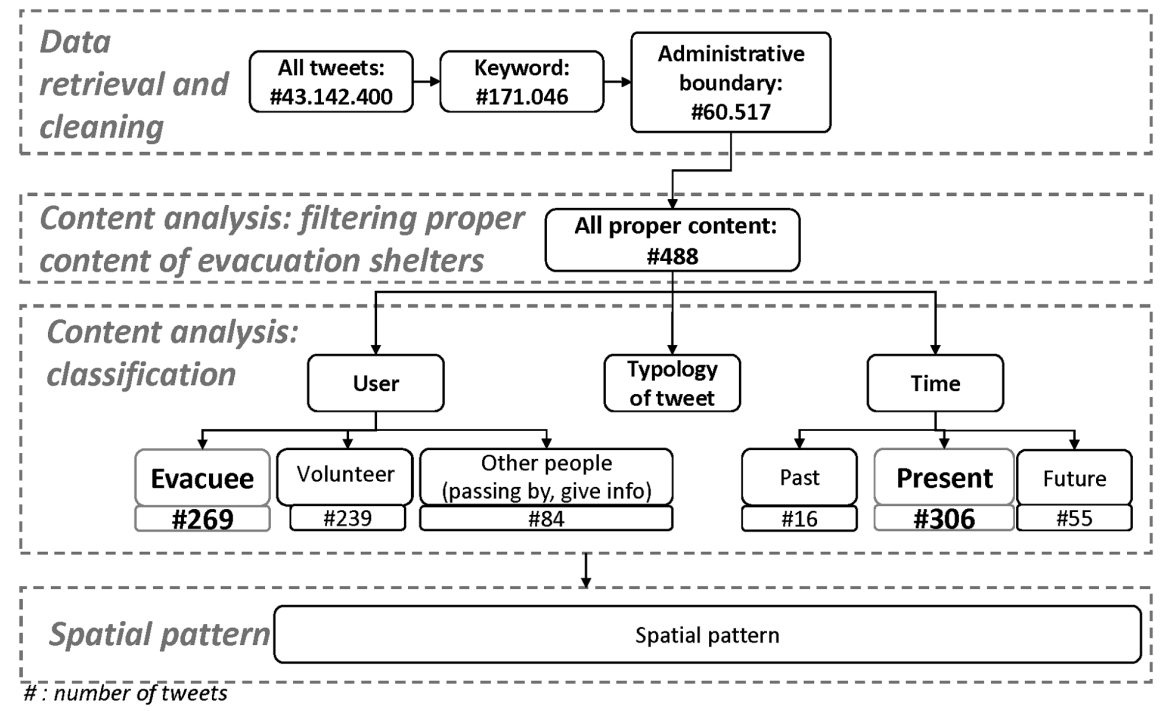

FIGURE 18.4 Flowchart of the analysis of Twitter data.

Atlas.ti ${ }^{\mathrm{TM}}$ software was used to check the validity - and thus relevance - of tweets to the topic of evacuation shelters. The purpose of this check was to filter for tweets that were contextually relevant to flood evacuation shelters in Jakarta. We used a deductive approach for content classification analysis, starting with predefined keywords regarded by an expert (in this case, the researcher in cooperation with Mrs Fitria Sudirman from Peta Jakarta) as being relevant. For instance, keywords like \#banjir (flood) and \#evakuasi (evacuation), and related words derived from the same roots (see also Section 18.2.1 above) (Holderness and Turpin, 2015), were used to determine relevant tweets.

Approximately 135,885 tweets were sent between December 2013 and March 2014, while 35,160 tweets were sent between December 2014 and March 2015. Subsequent data-frame clipping then yielded 60,517 tweets that were sent from within the administrative boundary of Jakarta Province (Figure 18.4 and Figure 18.5).

\subsubsection{Spatial Pattern of Twitter Users in or Near Evacuation Shelters}

People who send tweets with geo-location data indirectly disclose their location, as it can be collected from the geo-tagged tweet. However, there is a degree of inaccuracy in this. The Twitter location does not necessarily match the actual location of the person tweeting due to, for example, weak connectivity, the person tweeting being in motion or other forms of time lag between sending and reception. To deal with this inaccuracy, tweets can be grouped into spatial units in which the degree of accuracy required for data analysis is met.

\section{TABLE 18.1}

\section{Types and Sources of Secondary Data Used}

\begin{tabular}{|c|c|c|}
\hline Data & Year & Source \\
\hline Road & 2014 & Jakarta City Planning Department (DPK) \\
\hline Provincial boundary & 2014 & Jakarta City Planning Department (DPK) \\
\hline Flood area (flooded to a depth $>10 \mathrm{~cm}$ ) & $2002,2007,2014 / 15$ & $\begin{array}{l}\text { Jakarta Disaster Management Agency } \\
\text { Jakarta City Planning Department (DPK) }\end{array}$ \\
\hline Land use category & 2014 & Jakarta City Planning Department (DPK) \\
\hline Locations of official evacuation shelters & $2013 / 14 ; 2014 / 15$ & Jakarta City Planning Department (DPK) \\
\hline
\end{tabular}




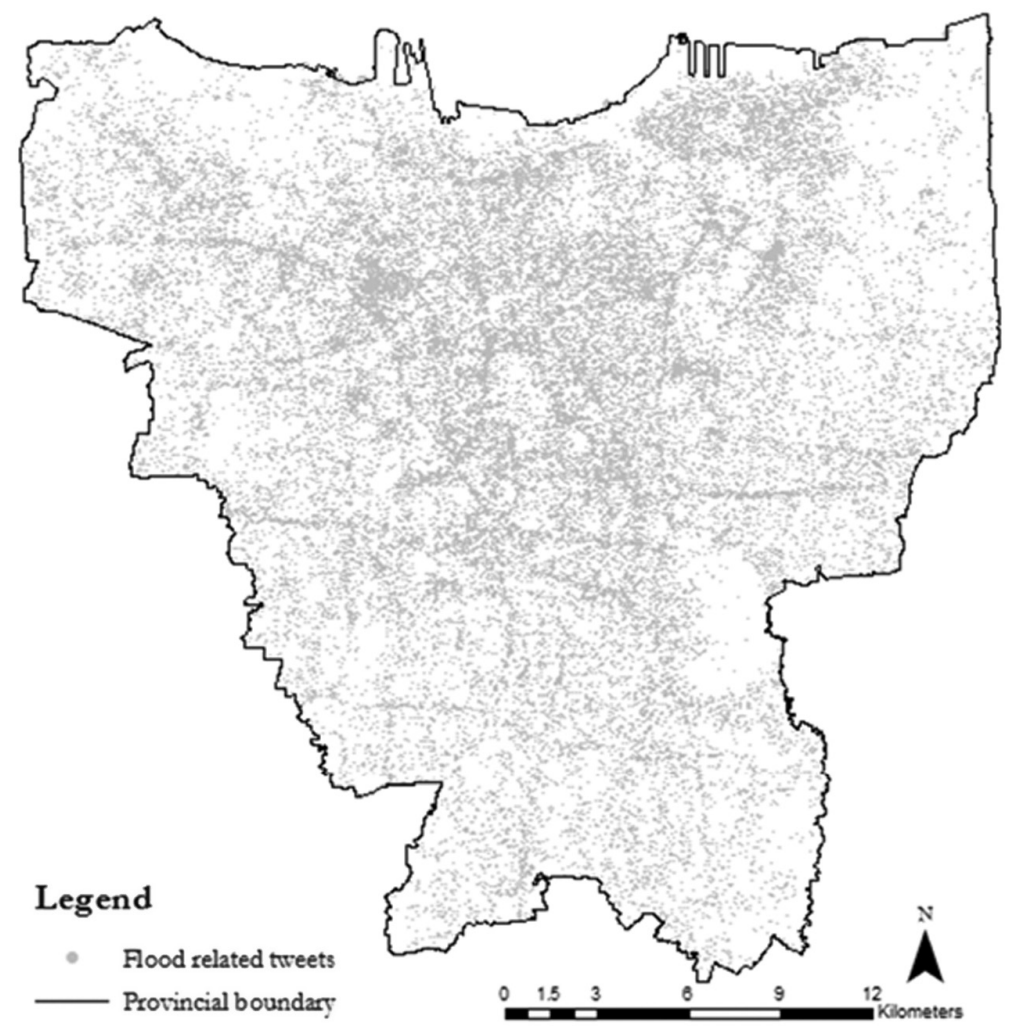

FIGURE 18.5 Source locations of 60,517 tweets related to the floods sent during the 2013/14 and 2014/15 floods in Jakarta Province.

The location of the Twitter data is obtained as a point feature, which can be ascribed to administrative boundaries or any other spatial unit (Poorthuis et al., 2014). The selection of the appropriate type of spatial unit is highly dependent on the purpose of the research, which in this case required using the smallest spatial unit available. Other scholars have used buildings or land-use categories when representing shelter sites (Chang and Liao, 2014; Gall, 2004; Kar and Hodgson, 2008).

It is necessary to consider the positional accuracy in order to select the most appropriate spatial unit. Many studies have investigated the accuracy of VGI (Goodchild and Li, 2012). Haklay (2010), for example, compared the data of Open Street Map with survey data, which showed an average deviation between the geo-location and actual location of $6 \mathrm{~m}$. In our study, the accuracy was assessed using the content of tweets as control data (Comber et al., 2013). Using purposive sampling, i.e. tweets that clearly mentioned the location of the person in the text, we were able to test the distance between the geo-location and the actual location. The mean distance was used as a basis for choosing the spatial unit.

\subsubsection{Shelter Preferences Among Twitter Users}

Analysis of residents' preferences for locations of evacuation shelters was conducted using a qualitative, comparative method that considered the following data:

- land use categories;

- evacuation shelters officially classified as such by Jakarta's planning boards;

- results of the questionnaire (insufficient due to low response rate). 
In our study, land use categories were used to categorise and characterise the location and preferences of evacuation shelters, because this is a categorization that is useful for urban planning and management. However, other studies might characterise evacuation shelters based on other features, such as height or age of the building, which may also be important characteristics. We determined the number of people tweeting from shelter sites located in each land-use category, and how many of them were at or near official evacuation shelters. In this way we were able to determine patterns of use of unofficial shelters and that of official evacuation shelters.

\subsection{RESULTS}

\subsubsection{Location of Twitter Users in or Near Evacuation Shelters}

Our analysis shows that during 2013/2014 and 2014/2015 floods, 306 tweets could be recognised as coming from locations of evacuation shelters. By overlaying the tweet data on the flooding maps of 2013/2014 and 2014/2015, we were able analyse the spatial distribution of tweet locations.

The locations of tweets for 2013/2014 were clustered in the central area of Jakarta - the Kampung Pulo neighbourhood of Jatinegara District - which was most severely affected by the flood event (Figure 18.6a). Some areas in Kampung Pulo are located on the floodplain of Jakarta's biggest river, the Ciliwung River. For many years the floodplain has been the location of slums, inhabited by low-income residents. Like many other slums (Kit et al., 2011), Kampung Pulo occupies an area where the risk of flooding is high (Khomarudin et al., 2014). In response to the higher risks faced in Kampung Pulo as compared with other locations in Jakarta, voluntary organisations have provided aid to set up evacuation shelters.

In comparison with the 2013/2014 flood event, the area of flooding in 2014/2015 was smaller and the impact of the flood event lower, which is most likely also the reason why there were fewer tweets during the 2014/2015 event. According to BPBD Jakarta (2015), the time of inundation from December 2013 to March 2014 was on the 4th, 20th, 20th and 8th days of the consecutive months, respectively; whereas from December 2014 to March 2015 inundation began on the 5th, 2nd, 7th and 4 th days of the consecutive months, respectively.

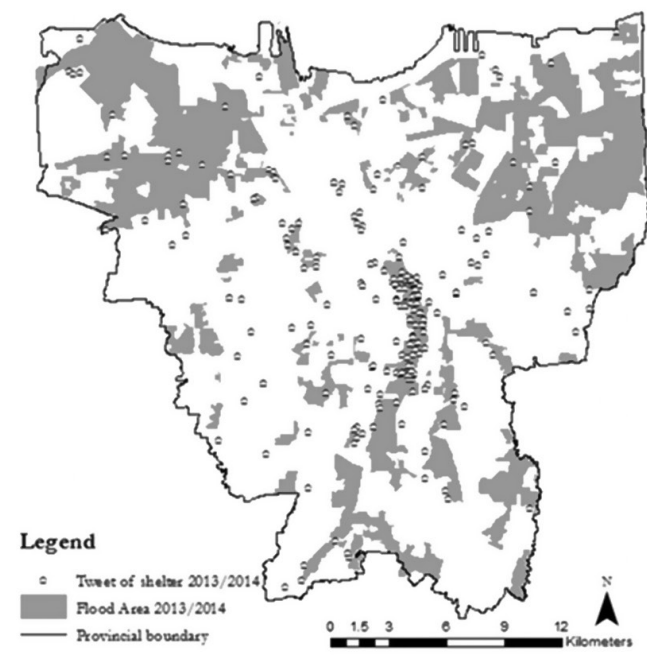

(a)

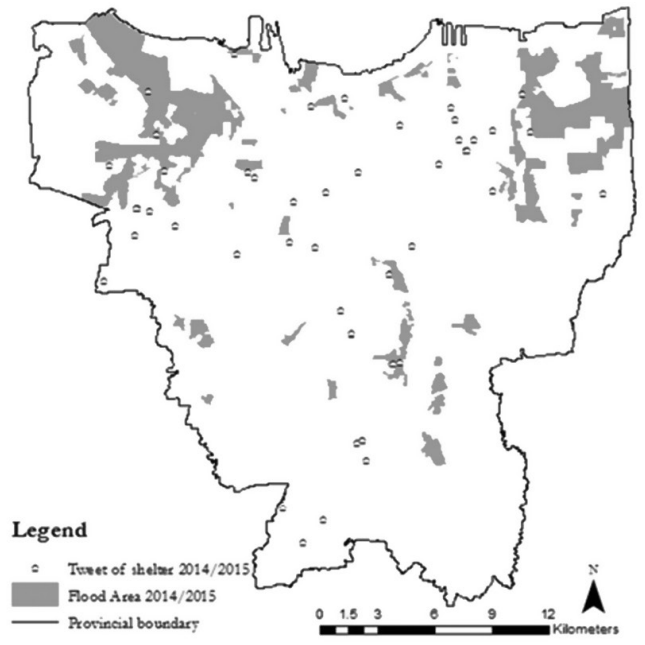

(b)

FIGURE 18.6 Tweets about evacuation shelters and flooded areas (a) 2013/14 and (b) 2014/15. (Data: Jakarta Disaster Management Agency (BPBD Jakarta); Jakarta Planning Board; Zook et al., 2016). 
Only 48 tweets mentioned evacuation shelters during the 2014/2015 flooding, while there were 258 tweets in the 2013/2014 floods. The tweets were dispersed over several locations throughout the city, rather than being concentrated in the area of flooding, as was the case for the 2013/2014 flood event (Figure 18.6b).

\subsubsection{Spatial Pattern of Twitter Users in or Near Evacuation Shelters}

Of the 306 tweets related to evacuation shelters, 86 mentioned the detailed location of the shelter. These 86 tweets were used as a sample to calculate the mean distance between the geo-location and the actual location based on what was mentioned in the tweet. The average distance between the geo-location and the actual location was $188.28 \mathrm{~m}$, ranging from 0 to $5,405 \mathrm{~m}$.

Since the distances between the geo-location and the actual location were quite large, each tweet point was converted so that its location was recorded as being within one of the spatial units selected for further analysis. This procedure helped to group tweets from different geo-locations that mentioned the same location in the tweeted text. There are several types of spatial units that could accommodate the mean distance of 188.28 metres. Buffers, hexagons and land-use zones are some of them.

The first spatial unit considered was that of land-use zones, i.e. polygons ranging in size from $3 \mathrm{~m}^{2}$ to $3 \mathrm{~km}^{2}$. If, however, we directly converted the point of tweets into land-use zone locations using spatial joining without buffering, the result could be misleading when the evacuation shelter lies close to a border between different land-use categories. Tweets that were actually posted close to, but not from within, evacuation shelters (or have been posted from within but were recorded as being outside due to transmission speed) could already belong to a different land-use zone.

Hexagon tessellations are commonly used to simplify point data (Raposo, 2013). According to Birch, Oom and Beecham (2007), hexagon tessellations have several advantages, for example, over regular square grids. The nearest neighbourhood is more symmetrical in a hexagonal tessellation as compared to a rectangular grid since the length of each line of the hexagon contour is equal. The width of hexagons has conformity, meaning that using hexagons allows an area to be covered without overlapping neighbourhoods. Data can also be visualised more clearly.

In our study, the hexagon used had sides of an equal length of $200 \mathrm{~m}$, based on the $188.28 \mathrm{~m}$ mean distance between geo-locations and actual locations. Following conversion, the 306 tweets from residents' evacuation shelters (points) were located in 215 hexagons representing residents' shelter sites.

\subsubsection{Preferences for Evacuation Shelters Among Twitter Users}

Twitter users' preferences for evacuation shelters were analysed using results from the questionnaire combined with the spatial pattern of the hexagons. Responses to the questionnaire came from people identified as evacuees - in contrast to volunteer workers, for example. In total, 269 relevant tweets sent from 184 Twitter accounts were identified as having been sent by evacuees. However, evacuees and volunteers could not always be differentiated. For example, when residents mentioned 'I am at an evacuation shelter' or only gave general information about the evacuation shelters, these have been classified as 'other people'.

In order to get information on the location preferences of evacuees, we sent the link to a questionnaire to the 184 Twitter accounts of evacuees. Several challenges were encountered in getting feedback from them. At first, people tended to ignore the questionnaire altogether, which led us to send several reminders. After six reminders over the course of six days, only three Twitter account users had provided feedback on their preferences. The low number of questionnaires returned lends support to one of our initial arguments: that obtaining information about preferences of shelter use is difficult to obtain through traditional methods of data collection, i.e. questionnaires. Another challenge was the limited number of characters (140) allowed in Twitter, which restricted the amount of information we could provide to introduce the questionnaire. 
Subsequently, we used the distance of evacuation shelters from the flood area as one of the criteria determining residents' preferences in selecting an evacuation shelter (American Red Cross, 2002; FEMA, 2015; Kar and Hodgson, 2008). From the mean distance of the location of each resident's evacuation shelter to the nearest flood-prone area, we found that shelter sites in Jakarta were mostly located within flood-prone areas. About $60 \%$ of the sites of residents' evacuation shelters (hexagons) in Jakarta were within an area flooded in 2013/14 and/or 2014/15 (Figure 18.7). One explanation for this high number is that people tend to look for a safe location near their home. For example, some evacuees take refuge on the second floor of a neighbour's house.

Kongsomsaksakul, Yang and Chen (2005) mention that the ideal location for an evacuation shelter is outside the flooded area, but within $1 \mathrm{~km}$ of it. In the case of Jakarta, about $31 \%$ of residents' shelter sites (hexagons) meet this criterion - a fact that was also confirmed by answers in the questionnaire - indicating that evacuation shelters used by respondents were located very close to the flooded area (i.e. distances of between $200 \mathrm{~m}$ and $1 \mathrm{~km}$ ).

Respondents mentioned that the main reason for their choice of evacuation shelters was accessibility, safety from flooding and proximity to their home. Accessibility is clearly an important factor for people considering where to go when they have to evacuate (CCCMCluster, 2014; Tai et al., 2010). One respondent added that the closeness of the evacuation shelter to their house allowed them to monitor conditions at their home at any time. The average distance from shelters to respondents' houses was 200-300 m. Another respondent, however, mentioned that his shelter was $2 \mathrm{~km}$ away from his house. He added that this shelter, provided by a religious organization, was the closest one he could reach.

All respondents stated that they travelled to evacuation shelters on foot - none used a car, motorbike or public transportation. This is consistent with research by Chang and Liao (2014), who found that people chose to walk rather than drive to evacuation shelters. In contrast, Kar and Hodgson (2008) assumed that people usually travelled by car to the shelters. The mode of transport used to reach evacuation shelters is also dependent on the type and impact of a flood. For example, one tweet used in this study stated that the person tweeting had to use a rescue boat to reach an
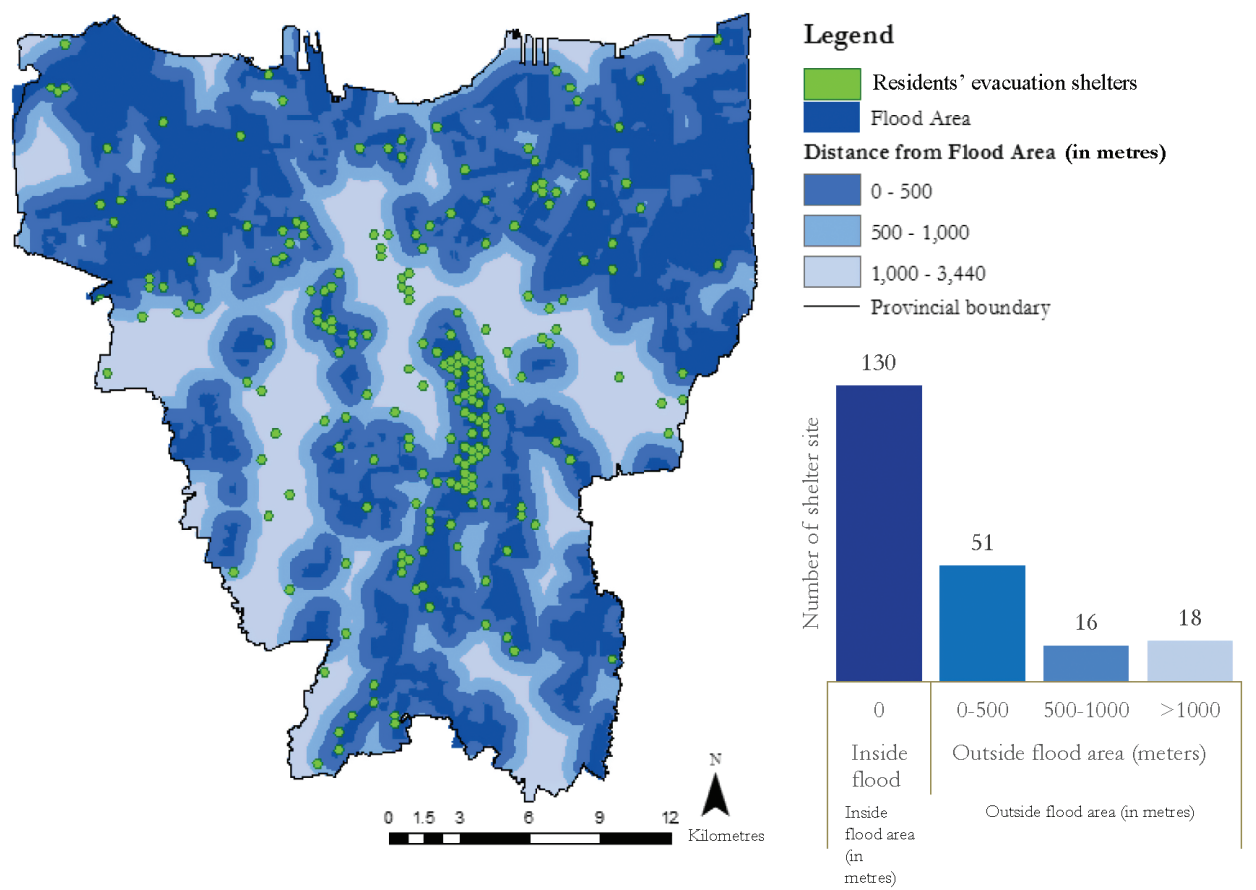

FIGURE 18.7 Distance between residents' evacuation shelters and flood areas. (Data: Jakarta Disaster Management Agency (BPBD Jakarta, 2013, 2015; Jakarta Planning Board, 2002, 2007; Zook et al., 2016). 
evacuation shelter. According to our findings, however, the walking distance to the shelter should be the main factor considered when planning evacuation shelters in Jakarta.

Additionally, we identified the land-use types coinciding with the locations of residents' evacuation shelters on a land-use map. It was not always possible to locate the shelter precisely on a particular type of land use since the spatial unit for shelters are hexagons, and a hexagon can contain several types of land use. Thus, our analysis could only provide a general overview of types of land use preferred for the location of evacuation shelters.

However, results show that the evacuation shelters are mostly located in open/green spaces. This is also the land-use type most frequently used when siting official evacuation shelters provided by the government. Some of these official shelters were tents, rather than permanent buildings, e.g. the central evacuation shelter of Jakarta. This shelter was located in one of the largest open/green spaces in the city, where it also served as a logistics and coordination centre. Another tent shelter was located at the train station, erected in a park that is part of the buffer zone alongside the railway. The second most common land-use type for the location of unofficial shelters was residential land. Many people found shelter near their home, often provided by neighbours or family members. Several tweets sent by volunteers indicated that they had opened their houses as a temporary shelter for their neighbours. Offices were the third most common type of land use used for unofficial shelters, at sites mainly chosen by residents. Tweets indicate that several shelters were located in the basements of office buildings. Figure 18.8 shows the distribution of land-use types used for unofficial evacuation shelters.

\subsubsection{Comparison of Sites of Official and Unofficial Evacuation Shelters}

By comparing the siting of unofficial evacuation shelters and those of official evacuation shelters, we were able to obtain an overview of people's use of official evacuation shelters. At the time of our study, there were 2,645 official evacuation shelters.

The spatial unit that shows the location of official evacuation shelters is based on land-use zones, which are different from the hexagons that identify the sites of unofficial evacuation shelters. Hence, it is not possible to determine with absolute certainty whether or not residents used the official evacuation shelters, even when the determined location of the tweeting resident was very close to an official shelter site. To deal with this issue, we analysed the spatial join between official and residents' shelter sites, assuming that the intersection of an official evacuation shelter with the hexagon of a residents' evacuation shelter site points to the use of an official evacuation shelter. Our analysis yields an intersection of $35.6 \%$, indicating that about a third of the residents' shelter sites intersected with official evacuation shelters (Figure 18.9).

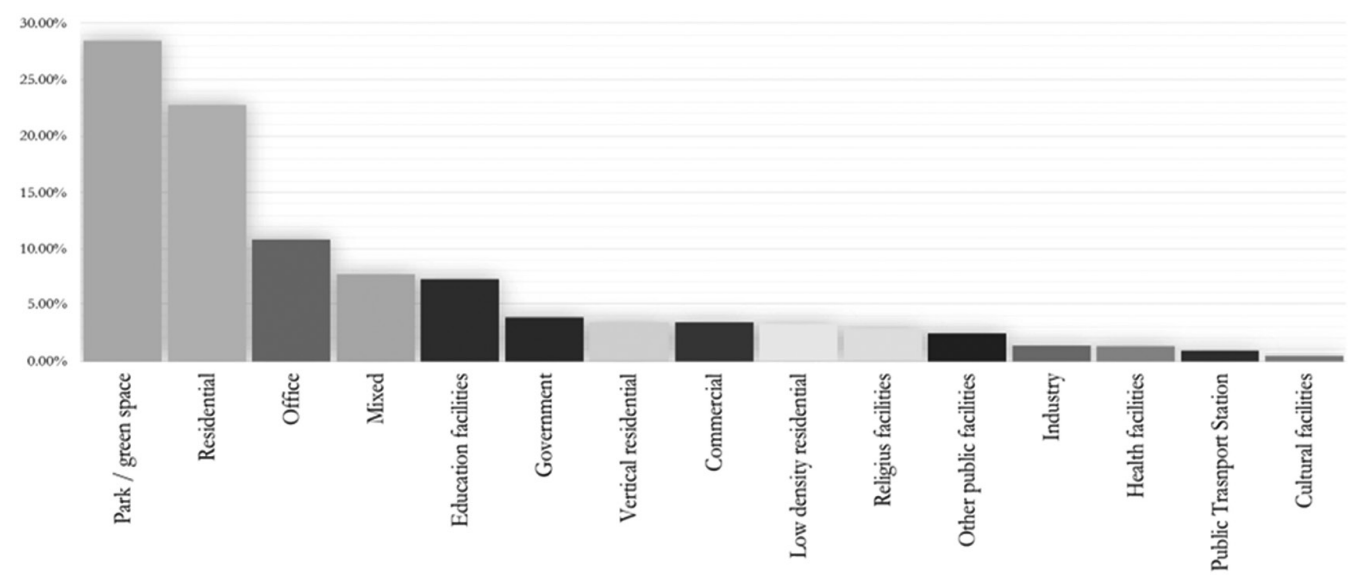

FIGURE 18.8 Type of land use at locations used for unofficial evacuation shelters. (Data: Jakarta Capital City Government, 2014). 


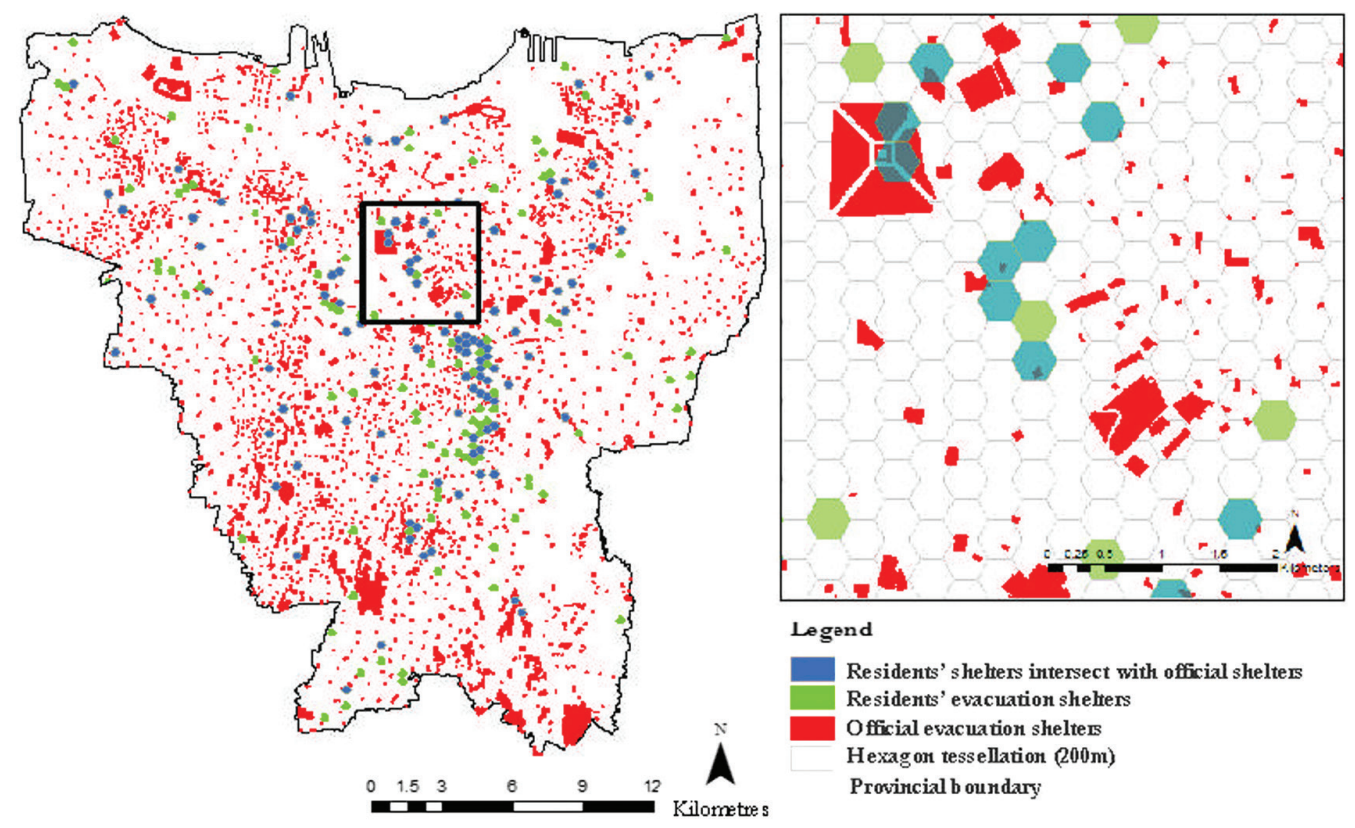

FIGURE 18.9 Intersection of residents' shelter sites with official evacuation shelters. The right inset shows a close-up as an example. Red polygons mark official evacuation shelters. Blue hexagons show residents' shelter sites that intersect with the location of official evacuation shelters. Green hexagons show residents' shelters that do not coincide with official shelters. (Data: Jakarta Capital City Government, 2014; Zook et al., 2016).

Our results show that $53.5 \%$ of the cases where official shelters and residents' shelter locations coincided were educational centres. Green space was the second most common type of land use upon which official and residents' shelters coincided - accounting for $29.6 \%$ of the total. The remaining cases concerned religious, health or sports centres.

In their daily lives, people use and are familiar with education centres, so they are aware of their locations. Moreover, education centres can be found in every neighbourhood of Jakarta: there are about 2,700 public schools and 4,100 private schools of all levels (DKI Jakarta Province Government, 2015).

Our results suggest that the sparse use of official evacuation shelters relates to people's lack of awareness. In response to the questionnaire, respondents mentioned that they never used the official evacuation shelters because they did not know they existed. One respondent mentioned that official evacuation shelters are only set up when flooding occurs. Moreover, if no evacuation shelters were provided by the government, respondents indicate that they would prefer to go to a neighbour's house or that of a family member that was safer than their house. Two of the respondents mentioned that they often shelter at sites known from their daily activities, one being a religious centre and the other the home of family members. Location preferences were strongly influenced by the familiarity that evacuees felt with the shelter site.

In this respect, our analysis shows that social networks in a community are also very important when disasters occur. Analysis of VGI data has provided important insights into the distribution and patterns of use of unofficial and official evacuation shelters during flood events in Jakarta.

\subsection{DISCUSSION}

Analysis shows that using VGI for disaster planning and management has more potential applications than just capturing real-time information (Erskine and Gregg, 2012). In this study, we have focused on information relating to evacuation shelters during flood events. As a result, the location 
of unofficial evacuation shelters used by evacuees during floods could be identified. We have shown that the general pattern of evacuation-shelter locations captured using VGI could provide important inputs for evacuation-shelter planning.

This research applies to a large area, some $662 \mathrm{~km}^{2}$. Nevertheless, residents' preferences for evacuation-shelter locations could be determined in a relatively short time. Using just the VGI data, we were also able to map the distribution of evacuation shelters without conducting a field survey. Obtaining the same information using traditional data collection methods would have been timeconsuming and costly (e.g. Mooney et al., 2011). Our study shows that VGI has potential as a costeffective substitute for traditional data collection methods.

Another benefit of using VGI, and specifically Twitter datasets, is the ease it offers in selecting and accessing information. The analysis of Twitter content uncovered various types of information related to the evacuation shelters. Firstly, VGI analysis could identify different types of users based on the content of their tweets. In our research, Twitter users were classified as either volunteers, representatives of government agencies and NGOs or evacuees. Evacuees were then selected for a questionnaire on preferences regarding evacuation shelters. Thus, VGI was in this case also a platform for identifying potential survey participants as a sample of the population. Moreover, through content analysis - based on the use of verb tenses in tweeted sentences - we were also able to identify the time frame of tweets. We could, for example, identify who was in an evacuation shelter at the time they sent their tweet. Using this type of information, we could pinpoint the location of shelters more accurately.

Nevertheless, content analysis of tweets can be time-consuming and potentially could reduce the advantage of time-efficiency. Choosing proper keywords is therefore crucial, as are adjustments in keywords in the iterative process of content analysis. Several factors need to be considered. First, in filtering the content of the tweets, synonyms of each keyword should be considered. Some people may use another word with the same meaning as a more common alternative. Slang should also be included, especially if the users are young people. Moreover, adjectives, verbs and nouns formed from the same root-word all need to be included. Another factor to consider is the use of metaphors. Keywords are influenced by the characteristics of each language, and the same keyword may have many connotations. All these aspects were taken into account in the content analysis of tweets for our study. However, despite the care taken to guarantee consistent output in the content analysis, unorthodox use of language and particularly the use of metaphors could lead to the inclusion of tweets whose content is not relevant to the topic under consideration - a possibility that cannot be ruled out completely.

There are other drawbacks with using VGI. The problem of geographic (in)accuracy is currently a concern of many researchers. It was also an issue in this study. The accuracy assessment established considerable deviation between the geo-location supplied with the Twitter data and the actual location mentioned in the content of tweets. There are many possible explanations for this. One possible reason is that people tweet while moving; this would affect the geo-location, particularly if a time interval elapsed before the tweet was sent. It is also possible that people send tweets about their experiences in a shelter after moving away from that location. Poorthuis et al. (2014) argue that various technologies of geo-tagging have issues with accuracy. Many types of GPS and Wi-Fi also influence the accuracy of geo-tagging. Despite these shortcomings, our analysis shows that the advantages of using VGI data outweigh potential disadvantages.

Our study suggests that VGI can be used in the planning/siting of evacuation shelters using the feedback from targeted respondents. Evacuees were asked to answer a questionnaire sent to their Twitter account. Unfortunately, we received only three responses out of a total of 184 accounts to which the questionnaire was sent. When people were confronted with a long list of questions on an issue that had long passed, i.e. the flooding crisis, they did not respond. We conclude, therefore, that Twitter is not a useful platform for getting in-depth feedback from residents: careful content analysis of the tweets was the main source of information in this study. This result contradicts Brabham (2009), who maintains that VGI has the potential to elicit active public participation in urban planning projects. Our analysis shows that Twitter works best as a source of information 
provided voluntarily by residents. Requesting people to respond and participate more actively in urban planning initiatives was not successful in this case.

Overall, our analysis was able to capture residents' preferences regarding siting of evacuation shelters through VGI and location identification. The pattern analysis of these shelter locations was an important step in investigating why people prefer a certain shelter (both official and unofficial) or why not - a crucial piece of information for future planning of evacuation shelter sites. Some of the technical limitations encountered could be overcome, at least in part, by using VGI in combination with other approaches, such as participatory mapping. Goodchild and Li (2012) see the role of VGI mainly in the initial and hypothesis-generating step of research, this due to technological limitations (e.g. accuracy). Overall, however, our analysis provides important insights into how the planning, organization and notification of official residents' evacuation shelters can be improved.

\subsection{CONCLUSION}

This research described in this chapter was focused on using VGI in evacuation shelter planning/ siting as one crucial part of emergency response.

Our results show that $35.6 \%$ of people who sent tweets from evacuation shelters may have been using an official evacuation shelter. Overall, the most frequently used land-use category for evacuation shelters was 'green/open spaces'. In the case of official shelters, this was followed by the landuse type 'schools and education centres'. We conclude that people only used the official shelters when they knew of the location from their daily activities. The issue of unfamiliarity goes a long way to explaining the failure by residents to use official shelters near their homes.

Overall, VGI is a useful approach for capturing residents' preferences for particular evacuation shelters, when used in conjunction with, for example, land-use data. VGI data provide a preliminary overview of any topic of interest in the form of data of a general nature that covers a broad area. Our research shows, however, that VGI should be combined with other approaches to fully understand residents' preferences for specific spatial planning problems.

\section{REFERENCES}

Akmalah, E., \& Grigg, N. S. (2011). Jakarta flooding: Systems study of socio-technical forces. Water International, 36(6), 733-747. https://doi.org/10.1080/02508060.2011.610729

American Red Cross. (2002). Standards of Hurricane Evacuation Shelter Selection.

Birch, C. P. D., Oom, S. P., \& Beecham, J. A. (2007). Rectangular and hexagonal grids used for observation, experiment and simulation in ecology. Ecological Modelling, 206(3-4), 347-359. https://doi.org/ 10.1016/j.ecolmodel.2007.03.041

BPBD Jakarta. (2015). Flood Map Jakarta (in Bahasa).

Brabham, D. C. (2009). Crowdsourcing the public participation process for planning projects. Planning Theory, 8(3), 242-262. https://doi.org/10.1177/1473095209104824

Carley, K. M., Malik, M., Landwehr, P. M., Pfeffer, J., \& Kowalchuck, M. (2015). Crowd sourcing disaster management: The complex nature of Twitter usage in Padang Indonesia. Safety Science, 90, 48-61. https://doi.org/10.1016/j.ssci.2016.04.002

CCCMCluster. (2014). The Mend Guide Comprehensive Guide for Planning Mass Evacuations in Natural Disasters.

Chang, H.-S., \& Liao, C.-H. (2014). Planning emergency shelter locations based on evacuation behavior. Natural Hazards, 76(3), 1551-1571. https://doi.org/10.1007/s11069-014-1557-x

Comber, A., See, L., Fritz, S., Van der Velde, M., Perger, C., \& Foody, G. (2013). Using control data to determine the reliability of volunteered geographic information about land cover. International Journal of Applied Earth Observation and Geoinformation, 23, 37-48. https://doi.org/10.1016/j.jag.2012.11.002

DKI Jakarta Province Government. (2015). Number of Schools in Jakarta (in Bahasa).

Durahim, A. O., \& Coşkun, M. (2015). \#iamhappybecause: Gross National Happiness through Twitter analysis and big data. Technological Forecasting and Social Change, 99, 92-105. https://doi.org/10.1016/ j.techfore.2015.06.035 
Erskine, M. A., \& Gregg, D. G. (2012). Utilizing volunteered geographic information to develop a real-time disaster mapping tool: A prototype and research framework. In International Conference on Information Resources Management (Conf-IRM) (p. Paper 27).

FEMA. (2015). Safe Rooms for Tornadoes and Hurricanes: Guidance for Community and Residential Safe Rooms. Washington D.C.

Firman, T., Surbakti, I. M., Idroes, I. C., \& Simarmata, H. a. (2011). Potential climate-change related vulnerabilities in Jakarta: Challenges and current status. Habitat International, 35(2), 372-378. https://doi.org /10.1016/j.habitatint.2010.11.011

Gall, M. (2004). Where to go? Strategic modelling of access to emergency shelters in Mozambique. Disasters, 28(1), 82-97. https://doi.org/10.1111/j.0361-3666.2004.00244.x

Goodchild, M. F. (2007). Citizens as sensors: The world of volunteered geography. GeoJournal, 69(4), 211-221. https://doi.org/10.1007/s10708-007-9111-y

Goodchild, M. F., \& Li, L. (2012). Assuring the quality of volunteered geographic information. Spatial Statistics, 1, 110-120. https://doi.org/10.1016/j.spasta.2012.03.002

Google. (2015). Google Maps.

Haklay, M. (2010). How good is volunteered geographical information? A comparative study of OpenStreetMap and ordnance survey datasets. Environment and Planning B: Planning and Design, 37(4), 682-703. https://doi.org/10.1068/b35097

Holderness, T., \& Turpin, E. (2015). From Social Media to GeoSocial Intelligence: Crowdsourcing Civic Co-management for Flood Response in Jakarta, Indonesia. In S. Nepal, C. Paris, \& D. Georgakopoulos (Eds.), Social Media for Government Services (pp. 115-133). Springer International Publishing. https:// doi.org/10.1007/978-3-319-27237-5_6

Jakarta Capital City Government. (2014). Detailed Spatial Plan and Zoning Regulation (In Bahasa), Pub. L. No. $1 / 2014,1$.

Kar, B., \& Hodgson, M. E. (2008). A GIS-based model to determine site suitability of emergency evacuation shelters. Transactions in GIS, 12(2), 227-248. https://doi.org/10.1111/j.1467-9671.2008.01097.x

Khomarudin, R., Suwarsono, Ambarwati, D. O., \& Prabowo, G. (2014). Flood Event Evaluation in Kampung Pulo DKI Jakarta and Risk Reduction Analysis Using Unmanned Air Vehicle (UAV) and High Resolution Remote Sensing (English Abstract) (in Bahasa). In LAPAN (Ed.), Seminar Nasional Penginderaan Jauh (pp. 611-619). Jakarta: LAPAN.

Kit, O., Lüdeke, M., \& Reckien, D. (2011). Assessment of Climate Change-Induced Vulnerability to Floods in Hyderabad, India, Using Remote Sensing Data. In K. Otto-Zimmermann (Ed.), Resilient Cities: Cities and Adaptation to Climate 35 Change Proceedings of the Global Forum 2010 (pp. 35-44). Springer Netherlands. https://doi.org/10.1007/978-94-007-0785-6

Kongsomsaksakul, S., Yang, C., \& Chen, A. (2005). Shelter location-allocation model for flood evacuation planning. Journal of the Eastern Asia Society for Transportation Studies, 6, 4237-4252.

Kreiner, K., \& Neubauer, G. (2012). Social Media for Crisis Management: Problems and Challenges from an IT-Perspective. In 20th Conference of Interdisciplinary Information Management Talks. Jindřichův Hradec.

Mooney, P., Sun, H., \& Yan, L. (2011). VGI as a Dynamically Updating Data Source in Location-Based Services in Urban Environments. In Proceedings of the 2nd International Workshop on Ubiquitous Crowdsourcing - UbiCrowd'l1 (p. 13). New York, New York, USA: ACM Press. https://doi. org/10.1145/2030100.2030105

Perry, R. W. (1979). Incentives for evacuation in natural disaster research based community emergency planning. Journal of the American Planning Association, 45(4), 440-447. https://doi.org/10.1080/019443 67908976988

Poorthuis, A., Zook, M., Shelton, T., Graham, M, and Stephens, M. 2016. Using Geotagged Digital Social Data in Geographic Research. In Key Methods in Geography. eds. Clifford, N., French, S., Cope, M., and Gillespie, T. London: Sage. 248-269.

Rahman, A., Mallick, F., Mondat, S., \& Rahman, M. R. (2014). Flood Shelters in Bangladesh: Some Issues from the Users Perspective. In A. E. Collins \& S. Akerkar (Eds.), Hazards, Risks and Disasters in Society (Illustrated, p. 425). Elsevier.

Raposo, P. (2013). Scale-specific automated line simplification by vertex clustering on a hexagonal tessellation. Cartography and Geographic Information Science, 40(5), 427-443. https://doi.org/10.1080/ 15230406.2013.803707

Schade, S., Díaz, L., Ostermann, F., Spinsanti, L., Luraschi, G., Cox, S., ... De Longueville, B. (2011). Citizenbased sensing of crisis events: sensor web enablement for volunteered geographic information. Applied Geomatics, 5(1), 3-18. https://doi.org/10.1007/s12518-011-0056-y 
Semiocast. (2012). Twitter reaches half a billion accounts - more than 140 million in the U.S.

Smart Insights. (2015). 2015 Social network popularity by country, 861, 2014-2016.

Stein, R. M., Duenas-Osorio, L., \& Subramanian, D. (2010). Who evacuates when hurricanes approach? The role of risk, information, and location. Social Science Quarterly, 91(3), 816-834. https://doi.org/10.1 111/j.1540-6237.2010.00721.X

Tai, C.-A., Lee, Y.-L., \& Lin, C.-Y. (2010). Urban disaster prevention shelter location and evacuation behavior analysis. Journal of Asian Architecture and Building Engineering, 9(1), 215-220. https://doi. org/10.3130/jaabe.9.215

Takahashi, B., Tandoc, E. C., \& Carmichael, C. (2015). Communicating on Twitter during a disaster: An analysis of tweets during Typhoon Haiyan in the Philippines. Computers in Human Behavior, 50, 392-398. https://doi.org/10.1016/j.chb.2015.04.020

Team Mirah Sakethi. (2010). Why flood in Jakarta: http://bpbd.jakarta.go.id/assets/attachment/study/buku_ mjb.pdf.

Wendling, C., Radisch, J., \& Jacobzone, S. (2013). The Use of Social Media in Risk and Crisis Communication. OECD Working Papers on Public Governance No. 24. https://doi.org/10.1787/5k3v01fskp9s-en

World Population Review. (2018). Jakarta Population 2018. Retrieved from http://worldpopulationreview.com/ world-cities/jakarta-population/

Zook, M., Graham, M., Shelton, T., Stephens, M., \& Poorthuis, A. (2016). floatingsheep: DOLLY. 


\section{$\Longrightarrow$ Taylor \& Francis Taylor \& Francis Group http://taylorandfrancis.com}

